\title{
A LONGITUDINAL DESCRIPTIVE STUDY ON RETINOPATHY OF PREMATURITY IN A TERTIARY CARE CENTRE IN SOUTH INDIA
}

\author{
Mary Thomas 1 , Sri Gautham Bodduluri2, Krishnaja Mandava33, M. Muthayya ${ }^{4}$, Binu Ninan 5 \\ ${ }_{1}^{1}$ Associate Professor, Department of Ophthalmology, Sri Ramachandra Medical College \& Research Institute, Porur, Chennai. \\ ${ }^{2}$ Post Graduate Student, Department of Ophthalmology, Sri Ramachandra Medical College \& Research Institute, Porur, Chennai. \\ ${ }^{3}$ Post Graduate Student, Department of Ophthalmology, Sri Ramachandra Medical College \& Research Institute, Porur, Chennai. \\ ${ }^{4}$ Professor, Department of Ophthalmology, Sri Ramachandra Medical College \& Research Institute, Porur, Chennai. \\ 5 Professor, Department of Neonatology, Sri Ramachandra Medical College \& Research Institute, Porur, Chennai.
}

\begin{tabular}{l}
\hline ABSTRACT \\
\hline BACKGROUND \\
To find out the incidence of threshold Retinopathy of Prematurity, its association with birth weight and gestational age and \\
outcome of management in a tertiary care centre.
\end{tabular}

\section{MATERIALS AND METHODS}

A longitudinal descriptive study by retrospective analysis of records. Screening was done for all neonates of $<30$ weeks gestational age and $<1500$ grams of birth weight and also those with unstable clinical course in the neonatal care unit in a University Hospital in South India. First assessment was done at 4 weeks of postnatal age or within 31 weeks of post-conceptional age whichever is later and then at 1-2 weeks interval until the retina was fully vascularised. Stage $3+$ were given laser. Aggressive posterior retinopathy of prematurity was treated with intravitreal injection of Bevacizumab (Avastin) followed by laser ablation of avascular retina.

\section{RESULTS}

Data was analysed by the statistical package for social sciences (SPSS for windows, version 16), 1535 babies were screened from January 2011 to December 2014, 63 neonates developed severe retinopathy and underwent treatment, 4 infants had aggressive posterior type, $23.8 \%$ were $>30$ weeks gestational age, $11.1 \%$ of infants were $>1500$ grams of birth weight. Threshold retinopathy was not seen above 35 weeks of gestational age and 1860 grams birth weight. All infants improved with treatment and vascularisation extended to periphery. None of them progressed to stage 4 or 5 .

\section{CONCLUSION}

Only $4.10 \%$ of the screened babies needed treatment and was in par with the standards of developed countries. Even with high standards of neonatal care in our centre, larger and heavier babies developed severe retinopathy. Being an institutional based small group study, this cannot be considered as a representation of the whole country and it is the limitation of this study. Correct identification of the threshold disease and prompt management will prevent severe visual disability in children and prevent them from being a burden to the family and society.

\section{KEYWORDS}

Retinopathy of Prematurity, Screening Programme, Gestational Age, Birth Weight.

HOW TO CITE THIS ARTICLE: Thomas M, Bodduluri SG, Mandava K, et al. A longitudinal descriptive study on retinopathy of prematurity in a tertiary care centre in South India. J. Evolution Med. Dent. Sci. 2016;5(30):1568-1572,

DOI: $10.14260 /$ jemds/2016/369

\section{INTRODUCTION}

Retinopathy of Prematurity (ROP), a vasoproliferative disease in the developing retina of premature babies, described by Terry in 1942.(1) (with implication of oxygen therapy due to the premature development of the lung, as the causative agent) is the main cause of visual impairment in preterm infants. It is a disease of smallest and sickest infants and can lead to blindness from vascular changes and gliosis resulting in vitreoretinal traction and retinal detachment unless recognised and treated early.

Financial or Other, Competing Interest: None.

Submission 23-02-2016, Peer Review 19-03-2016,

Acceptance 25-03-2016, Published 14-04-2016.

Corresponding Author:

Dr. Mary Thomas,

Associate Professor,

Department of Ophthalmology,

Sri Ramachandra Medical College \& Research Institute,

Porur, Chennai-600116, Tamilnadu, India.

E-mail: marysanthoshj@yahoo.co.in

DOI: $10.14260 /$ jemds $/ 2016 / 369$
The first case of the epidemic was seen on St. Valentine's Day in 1941, when a premature baby in Boston was diagnosed. The first epidemic of ROP occurred during 1940s and 1950s, mainly in developed countries due to unmonitored use of oxygen in premature babies. However, reports have found ROP in cases without oxygen therapy and even after oxygen therapy not all premature infants develop ROP.(2) A better understanding and management of oxygen therapy reduced the incidence of blindness later. With advances in neonatal intensive care more and more low Birth Weight (BW) and low Gestational Age (GA) infants surviving, 'Second Epidemic' of ROP began in 1970s and 1980s. From a global perspective, 'third epidemic' of ROP started mostly in the middle income countries.(3) As premature babies are now surviving at a greater rate, the inadequacy of resources and facilities and lack of experience with ROP screening and management resulted in increase in the incidence of blindness from ROP. Despite increased awareness and improvement in treatment, ROP accounts for $10 \%$ of blindness in developed countries. 
The prevalence of ROP varies globally in accordance with the socio-economic development of the countries, which in turn determines the survival of Extremely Low Birth Weight (ELBW) infants, proper screening and recognition of ROP and timely treatment.(4) Larger and greater GA babies were also found to have ROP in developing countries. This indicates that the present screening criteria for ROP is not entirely applicable in developing countries.

There are limited studies on the incidence and risk factors of this important morbidity among Very Low Birth Weight (VLBW) infants. (5-7) The global initiative for the elimination of avoidable blindness targets ROP for prevention of blindness and treatment in an effort to reduce the prevalence of childhood blindness. ( 8 )

In this institution based study, we try to estimate the incidence and severity of ROP in various GA and BW and to analyse the correlation with the age at which laser is started (Laser Week) for severe ROP and also the outcome of treatment. Though the number is small, VLBW (650 grams), Very Low Gestational Age (VLGA) babies (24 weeks) were also included in this study.

Though national screening program are available in many countries, they are expensive and they are stressful to infants. Screening for ROP, as stipulated by Joint Statement Guidelines of the American Academy of Paediatrics section on Ophthalmology is currently indicated for infants with $<1500$ grams of BW or GA of $<30$ weeks as well as infants with $>1500$ grams of BW or GA $>30$ weeks who are identified as 'High Risk' by their attending paediatrician or neonatologist. $(9,10)$

Fundus examination in VLBW preterm infants is technically difficult to perform requiring previous training and experience and adequate support from the nursing staff due to the poor health status of the preterm infants. In several occasions, examinations involve babies on ventilatory support with unstable vital signs, who are more prone to side effects of mydriatic eye drops (Especially cardiorespiratory complications, a mean increase of $6 \mathrm{mmHg}$ in diastolic pressure) and to eye manipulations by the ophthalmologist, (A further increase in both diastolic and systolic pressure of about $4 \mathrm{mmHg}$.(11) Therefore, the presence of the nursing staff throughout the procedure is extremely important in order to control and maintain an open airway to monitor the infant's vital signs and behaviour and to avoid life-threatening conditions.

\section{METHODS}

A longitudinal, descriptive study of 1535 babies who were screened for ROP from January 2011 to December 2014 in a University Hospital Based Neonatal Intensive Care Unit (NICU). Those children who died in between the screening were excluded from the study.

All examinations and treatments were performed by two ophthalmologist qualified to conduct ROP screening.

Binocular indirect Ophthalmoscopy was done for all neonates of $<30$ weeks of Gestational Age (GA) and Birth Weight (BW) of $<1500$ grams as well as babies of GA $>30$ weeks and BW of $>1500$ grams with unstable clinical course like mechanical ventilation, prolonged oxygen therapy, haemodynamic instability, septicaemia, intraventricular haemorrhage or cardiovascular problems. The zone of vascularisation was noted.
The number of total and contiguous clock hours of ROP and the presence or absence of plus disease (Dilatation and tortuosity of vessels in at least two quadrants in the posterior pole) were the important determinants of management.(12)

First assessment was done at 4 weeks of postnatal age or within 31 weeks of post-conceptional age (PCA - gestational age plus postnatal age in weeks), whichever is later using the schedule for follow-up recommended by joint statement of American Academy of Paediatrics (AAP), American Academy of Ophthalmology (AAO) and American Association of Paediatric Ophthalmology (AAPO)-published in 2013- until vascularisation of the retina reached temporal periphery or until full remission of ROP after treatment.(13)

Babies $<28$ weeks of GA and $<1200$ grams BW were screened early at 3 weeks of age for early identification of Aggressive Posterior Retinopathy of Prematurity (AP-ROP), characterized by severe plus disease in all 4 quadrants, flat neovascularization in zone 1 or posterior zone 2 , intraretinal shunting, haemorrhages and a rapid progression to retinal detachment without progressing through classic stages 1 to 3. $(14,15)$

Thereafter, follow-up examinations were done within two weeks' interval if retinal vessels had grown into zone II and every week for infants with vessels in zone I and more frequently if needed based on the retinal findings. The screening was done under a radiant warmer in the NICU. Discharged and stable babies were screened in the Ophthalmologist's clinic with pulse oximetry monitoring. Babies were comfortably wrapped in a thin blanket and examination was done 1 hour after a feed under topical anaesthesia (Proparacaine - $0.5 \%$ ) without any sedation using indirect ophthalmoscope and $20 \mathrm{D}$ lens.

Pupils dilated with $2.5 \%$ phenylephrine and $1 \%$ tropicamide instilled thrice at 5 minutes' interval. Eyelids are separated with Alphonso lid speculum. Scleral depression was done with wire vectis.

For threshold ROP laser ablation of the avascular retina anterior to the ridge was given. For APROP anti-VEGF monotherapy of Intravitreal Bevacizumab (IVB), $0.625 \mathrm{mg}$ in $0.025 \mathrm{~mL}$ given after getting an informed consent from the parents explaining the potential risk of the drug as well as the intravitreal injection. After a followup of 2-3 weeks, laser ablation of the whole avascular retina was done.

Though all international studies on ROP consider eyes with ROP in zone III as having good visual prognosis, we lasered zone III stage 3 ROP in case the regression was delayed or remained status quo for a long time and the result was fast reduction of the ridge and fast vascularisation to the periphery.

\section{Statistical Analysis}

Data was analysed by the Statistical Package for the Social Sciences (SPSS for windows, version 16). Descriptive statistics included the mean and standard deviation for numerical variables and the percentage of different categories for categorical variables. The prevalence rate of ROP was described in simple proportion. Group comparisons were done by the Chi-squared $\left(\mathrm{X}^{2}\right)$ test, a $\mathrm{p}$ value of $<0.05$ was considered significant.

\section{RESULTS}

The duration of the study was from January 2011 to December 2014. 
The study population included 1535 babies of $<30$ weeks GA and $<1500$ grams of BW as well as other premature infants with unstable clinical course in the neonatal care unit.

Out of 1535 babies evaluated, 749 (48.79\%) babies were males and 786 (51.20\%) were females. Babies from 24 weeks to 38 weeks and 650 grams to 2114 grams were screened.

Only those babies who underwent treatment for ROP were taken into analytical study. Out of 1535 babies who underwent screening, 63 babies developed threshold ROP. This included 4 APROP also. The GA of infants who developed threshold ROP were from 24-35 weeks with a mean of 28.7029. The BW ranged from 650 grams to 1860 grams with a mean of 1038.7302 [Table I]. The prevalence of severe ROP in this study is $4.10 \%$. None of them progressed to stage 4 or 5 ROP.

Gestational Age of babies who developed threshold ROP were 28 weeks or less in 30 infants (47.6\%), 30 weeks or less in 48 infants $(76.2 \%)$ and 15 infants $(23.8 \%)$ were $>30$ weeks; 2 of them were 34 weeks and one was 35 weeks. The youngest child who developed threshold ROP was 24 weeks of GA and threshold ROP was not seen beyond 35 weeks of GA [Table 2].

Birth weight of infants who developed threshold ROP were 1000 grams or less in 33 (52.4\%), 1500 grams or less in $56(88.9 \%)$ and $7(11.1 \%)$ were $>1500$ grams. The least eight seen was 650 grams and the highest weight seen was 1860 grams among the treated group [Table 3]. Threshold ROP was not seen beyond 35 weeks of GA and above 1860 grams BW.

We also analysed the PCA at which laser was given (laser week); $23(36.5 \%)$ were lasered at $<35$ weeks of PCA, 35 (55.6\%) were given lasered between 35-40 weeks of PCA, 5 (7.9\%) got lasered above 40 weeks of PCA who were in Zone III [Table 4].

Of the total 63 babies 30 were $<28$ weeks of GA, 18 were between 28-30 weeks. In $<28$ weeks' category laser week was either $<35$ weeks of PCA $(46.5 \%)$ or $35-40$ weeks of PCA (53.3\%). Between 28-30 weeks' category, 8 infants $(44.4 \%)$ were lasered at $<35$ weeks of PCA and $9(50 \%)$ were lasered at 35- 40 wks. PCA. Infants with $>30$ wks. of GA 10 (66.7\%) got laser between $35-40$ wks. and 4 (26.4\%) were lasered above 40 wks. of PCA.

It was observed that as the GA was increasing, the PCA at which laser given (laser week) was also increasing. This correlation between GA and laser week was found to be statistically significant with a P-value of 0.006 .

Another observation done was the correlation between GA and BW; 20 infants (66.7\%) were $<1000$ grams BW and $<28$ wks. of GA, 10 infants (55.6\%) were between $28-30$ wks. of GA and $<1000$ grams BW, 7 infants (46.7\%) were between 1000-1500 grams BW. As GA was increased, BW also increased and the number of children getting lasered. This was found to be statistically significant (P-value is 0.008).

All babies including APROP improved after treatment and vascularisation extended up to the periphery. Out of 1535 babies who underwent screening, 63 babies developed threshold ROP. This included 4 APROP also.

\section{DISCUSSION}

Substantial numbers of premature infants are affected by ROP worldwide. As more and more premature infants and VLBW babies survive with improved neonatal care without effective manpower (Trained ophthalmologist) and screening protocols the burden of ROP will be on the rise in the developing countries like India.

None of the babies in this study progressed to stage 4 or 5 , thus emphasising the result of timely screening, proper identification of stages of disease, prompt treatment and educating the parents about the need for regular follow-up and mentally preparing them regarding prognosis.

The parents of our babies were well informed about ROP and the consequences of missing the follow-up screening and timely laser/intravitreal Avastin injection and everybody was following up the instructions very carefully as opposed to the Chen et al. study from China, where one in eight eligible babies did not complete the ophthalmic examinations as parents did not bring them back after discharge.(16)

Overall, incidence of threshold ROP in this institutional study was comparable with most Western reports. This may be the result of judicial use of supplemental oxygen, prompt correction of conditions like anaemia, respiratory distress syndrome and the like. The incidence of ROP in various Western studies has been reported to vary from 21 to $65.8 \%$. $^{17-21)}$ In India the incidence of ROP is found to be $47.27 \%$. The incidence of ROP of any stage in our study was $18.45 \%$

The incidence of severe ROP only was taken into consideration in this study and was $4.10 \%$. At this juncture, it should be remembered that out of 63 children who underwent treatment, 7 were in zone III that increased the percentage. In a study conducted in at Wills Eye Hospital and Jefferson Medical College, both in Wyndmoor, Pennsylvania, 24 were identified and treated in a screening of 591 patients showing $4.1 \%$ incidence.(22)

An institutional cross-sectional study of preterm infants in Brazil in 2009 showed 5.4\% incidence.(23) Another study conducted in China, 7 out of 108 (6.4\%) babies developed threshold ROP.(24) Even with high standards of neonatal care in our hospital, among the babies who needed treatment, 15 infants $(23.81 \%)$ were $>30$ weeks of GA and 7 infants $(11.11 \%)$ were $>1500$ grams BW. Though the percentage of babies needing treatment for ROP in this institution based study was comparable to that of higher income countries, more mature and heavier babies were also affected by threshold ROP. Though small in number this cannot be ignored and points towards the need for widening the screening criteria. Highest BW where severe ROP developed was 1860 grams, whereas in a US based study no infants with BW more than 1500 g developed treatable ROP.(25)

Widening the screening criteria will dramatically increase the number of babies needing to be examined and increase the work load of ophthalmologist and staff in the neonatal unit. But the workload may not be as high as anticipated, because a high proportion of more mature babies will only need one examination, usually while they are still in the neonatal unit.(26)

The earliest PCA at which laser was started in this group is 31 wks. plus 2 days and the GA of that infant was 26 wks. plus 1 day. That means at the time of first screening itself the child was found to have ROP. According to CRYO-ROP study, threshold ROP is usually seen at 36.6 wks. of PCA (32-46 wks. variation).(27) In Asian countries, the entire sequence of events occurs one to two weeks earlier.(28)

Another important factor that has to be taken into consideration is whether the GA recorded in Indian scenario is 
reliable or not. In our study as shown in Table 4, as GA of baby increases the PCA at which laser given also is increased, i.e. window period for development of threshold ROP increased. Smaller babies have a shorter window period to develop threshold ROP. This is in contrast to the western studies where smaller babies have longer time margin to develop severe ROP. So an examination carried out earlier is important in Indian scenario as far as small GA babies are concerned.

\section{CONCLUSION}

Though the incidence of ROP in our institution based study is comparable with most western reports, older and heavier babies were also found to have developed severe ROP. As this is an institution based study, comprehensive country-wide study is needed to estimate the true incidence of ROP in India. Laser treatment is sufficient for managing zone II ROP. Laser therapy in APROP cases were found to be complicated by poor view of the fundus, because of persistent tunica vasculosa lentis, persistent foetal vasculature and anterior segment neovascularisation with non-dilating pupil. After Avastin injection, babies were monitored for 2-3 weeks before laser was given. Meanwhile plus disease regressed, better pupil dilatation in anterior segment neovascularisation, better media clarity and also babies grew in age and weight so that apnoeic attacks during laser was reduced.

ROP screening criteria may vary from institution to institution and country to country. So more coordinated prospective and multicentre studies and further meta-analysis is needed to develop a screening guideline suitable for Indian scenario.

Though any screening programme is time, money and energy consuming, our aim should be to prevent even a single child from losing vision due to ROP. Even widespread awareness programmes could be conducted in developing countries to prevent the development of severe ROP through elimination of preterm birth, improvement in neonatal care and implementing suitable screening guidelines.

\begin{tabular}{|c|c|c|c|c|c|}
\hline & N & Minimum & Maximum & Mean & $\begin{array}{c}\text { Std. } \\
\text { Deviation }\end{array}$ \\
\hline GA & 63 & 24.00 & 35.00 & 28.70 & 2.18 \\
\hline BW & 63 & 650.00 & 186.00 & 1038.73 & 313.31 \\
\hline $\begin{array}{c}\text { Laser } \\
\text { Week }\end{array}$ & 63 & 31.14 & 48.29 & 36.46 & 3.19 \\
\hline \multicolumn{7}{|c|}{ Table 1: Descriptive Statistics } \\
\hline
\end{tabular}

\begin{tabular}{|c|c|c|}
\hline & Frequency & Percentage \\
\hline$<28$ & 30 & 47.6 \\
\hline $28-30$ & 18 & 28.6 \\
\hline$>30$ & 15 & 23.8 \\
\hline Total & $\mathbf{6 3}$ & $\mathbf{1 0 0 . 0 0}$ \\
\hline \multicolumn{2}{|c|}{ Table 2: Gestational Age } \\
\hline
\end{tabular}

\begin{tabular}{|c|c|c|}
\hline & Frequency & Percentage \\
\hline$<1000$ & 33 & 52.4 \\
\hline $1000-1500$ & 23 & 36.5 \\
\hline$>1500$ & 7 & 11.1 \\
\hline Total & $\mathbf{6 3}$ & $\mathbf{1 0 0 . 0 0}$ \\
\hline \multicolumn{3}{|c|}{ Table 3: Birth Weight } \\
\hline
\end{tabular}

\begin{tabular}{|c|c|c|}
\hline & Frequency & Percentage \\
\hline$<35$ & 23 & 36.5 \\
\hline $35-40$ & 35 & 55.6 \\
\hline$>40$ & 5 & 7.9 \\
\hline Total & $\mathbf{6 3}$ & $\mathbf{1 0 0 . 0 0}$ \\
\hline \multicolumn{3}{|c|}{ Table 4: Laser Week } \\
\hline
\end{tabular}

\begin{tabular}{|c|c|c|c|c|c|}
\hline Status & ROP & No. & Mean & $\begin{array}{c}\text { Std. } \\
\text { Deviation }\end{array}$ & $\begin{array}{c}\text { Std. Error } \\
\text { Mean }\end{array}$ \\
\hline \multirow[b]{2}{*}{ GA } & APROP & 4 & 28.6429 & 1.56709 & 0.78355 \\
\hline & ROP & 59 & 28.7070 & 2.22462 & $\begin{array}{l}0.28962 \\
\text { Group } \\
\text { Statistics }\end{array}$ \\
\hline \multirow{2}{*}{ BW } & APROP & 4 & 1012.5000 & 218.38422 & 109.19211 \\
\hline & ROP & 59 & 1040.5085 & 320.02922 & 41.66426 \\
\hline \multirow{2}{*}{$\begin{array}{l}\text { Laser } \\
\text { Wk. }\end{array}$} & APROP & 4 & 32.4286 & 0.94761 & 0.47380 \\
\hline & ROP & 59 & 36.7288 & 3.10634 & 0.40441 \\
\hline \multicolumn{6}{|c|}{ Table 5: Group Statistics } \\
\hline
\end{tabular}

\section{ACKNOWLEDGEMENT}

The author wishes to acknowledge with gratitude the Department of Neonatology staff for providing care and support for the babies during the screening and treatment. Further, I acknowledge Dr. Ravi Shankar, Department of Community Medicine for the statistical assistance.

\section{REFERENCES}

1. Terry TL. Extreme prematurity and fibroblastic overgrowth of persistent vascular sheath behind each crystalline lens. I. preliminary report. Am J Ophthalmol 1942;25:203-4.

2. Chawala D, Agarwal R, Deorari A, et al. Retinopathy of prematurity. Indian J Pediatr 2008;75(1):73-6.

3. Gilbert C, Rahi J, Eckstein M, et al. Retinopathy of prematurity in middle income countries. Lancet 1997;350(9070):12-4.

4. Painter SL, Wilkinson AR, Desai P, et al. Incidence and treatment of retinopathy of prematurity in England between 1990 and 2011: database study. Br J Ophthalmol 2015;99(6):807-11.

5. Chang SY, Shu JL, Feng LH, et al. Retinopathy of prematurity: screening, incidence and risk factors analysis. J Chin Med Assoc 2001;64:706-12.

6. Chou YH, Teng RJ, Yau KI, et al. Retinopathy of prematurity: an analysis of risk factors. J Formos Med Assoc 1993;92(5):440-5.

7. Lin HJ, Lin CC, Tsai SW, et al. Risk factors for retinopathy of prematurity in very-low-birth-weight infants. J Chin Med Assoc 2003;66(11):662-8.

8. Wheatley CM, Dickinson JL, Mackey DA, et al. Retinopathy of prematurity: recent advances in our understanding. Arch Dis Child Fetal Neonatal Ed 2002;87(2):F78-82.

9. Hartnet ME, Penn JS. Mechanisms and management of retinopathy of prematurity. N Engl Med 2012;367(26): 2515-26.

10. American Academy of Paediatrics Section on Ophthalmology. American academy of ophthalmology, American association for paediatric ophthalmology and strabismus, American association of certified orthoptist. Screening examination of premature infants for retinopathy of prematurity. Pediatrics 2013;131:189. 
11. Laws DE, Morton C, Weindling M, et al. Systemic effects of screening for retinopathy of prematurity. Br J Ophthalmol 1996;80(5):425-8

12. The STOP-ROP Multicenter Study Group. Supplemental therapeutic oxygen for rethreshold retinopathy of prematurity (STOP-ROP): a randomized, controlled trial, primary outcomes. Paediatrics 2000;105:295-310.

13. American academy of paediatrics section on ophthalmology. American association for paediatric ophthalmology and strabismus. Screening examination of premature infants for retinopathy of prematurity. Paediatric 2006;117:572-6.

14. International committee for the classification of retinopathy of prematurity. The international classification of retinopathy of prematurity revisited. Arch Ophthalmol 2005;123:991-9.

15. Katz X, Kychenthal A, Dorta P. Zone I retinopathy of prematurity. J AAPOS 2000;4(6):373-6.

16. Palmer EA. Results of US randomized clinical trial of cryotherapy for ROP (CRYO-ROP). Doc Ophthalmol 1990;74(3):245-51.

17. Palmer EA, Flynn JT, Hardy RJ, et al. Incidence and early course of retinopathy of prematurity. Ophthalmology 1991;98(11):1628-40.

18. Fielder AR, Shaw DE, Robinson, et al. Natural history of retinopathy of prematurity: a prospective study. Eye 1992;6:233-42.

19. Acheson JF, Schulenburg WE. Surveillance for retinopathy in practice: experience from one neonatal intensive care unit. Eye 1991;5:80-5.
20. Holmstrom G, Azazi M, Jaconson, et al. Epidemiology of ROP in Stockholm area of Sweden. Acta Ophthalmol 1993;210:44-7.

21. Darlow BA. Incidence of retinopathy of prematurity in New Zealand. Arch Dis in Childhood 1988;63:1083-6.

22. Tasman W. Retinopathy of prematurity: do we still have a problem?: the Charles L. Schepens lecture. Arch Ophthalmol 2011;129(8):1083-6.

23. Fortes Filho JB, Eckert GU, Valiatti FB, et al. Prevalence of retinopathy of prematurity: an institutional crosssectional study of preterm infants in Brazil. Rev Panam Salud Publica 2009;26(3):216-20.

24. Chen Y, Li X, Yin H, et al. Risk factors for retinopathy of prematurity in six neonatal intensive care units in Beijing, China. Br J Ophthalmol 2008;92:326-31.

25. Yanovitch TL, Siatkowski RM, McCaffree MA, et al. Retinopathy of prematurity in infants with birth weight $\geq$ 1250 grams-incidence, severity and screening guideline cost-analysis. J AAPOS 2006;10(2):128-34.

26. Zin AA, Moreira ME, Bunce $C$, et al. Retinopathy of prematurity in 7 neonatal units in Rio de janeiro; screening criteria and work load implications. Paediatrics 2010;126(2):e410-7.

27. Schaffer DB, Palmer EA, Poltsky DF, et al. Prognostic factors in the natural course of retinopathy of prematurity. Ophthalmology 1993;100:230-7.

28. Kumar H, Shapiro MJ. A practical approach to retinopathy of prematurity screening and management. In: Kumar $\mathrm{H}$, Shapiro MJ, Azad RV, editors. ROP screening examination guidelines and methodology. New Delhi: Malhotra Enterprises; 2001;45-7. 